Volume 9, No.1.3, 2020

International Journal of Advanced Trends in Computer Science and Engineering

Available Online at http://www.warse.org/IJATCSE/static/pdf/file/ijatcse4291.32020.pdf

https://doi.org/10.30534/ijatcse/2020/4291.32020

\title{
Developing an Electrical Outlet using Internet of Things (IoT)
}

\author{
Maria Charmy A. Arispe ${ }^{1}$, Ryan B. Jaucian ${ }^{2}$, Arnold B. Platon ${ }^{3}$, Floradel S. Relucio ${ }^{4}$, Ben L. Saminiano ${ }^{5}$ \\ ${ }^{1}$ Bicol University Polangui Campus, Polangui, Albay, Philippines, cham.arispe@ gmail.com \\ ${ }^{2}$ Bicol University Polangui Campus, Polangui, Albay, Philippines, rbjaucian@ @icol-u.edu.ph \\ ${ }^{3}$ Bicol University Polangui Campus, Polangui, Albay, Philippines, abplaton@ bicol-u.edu.ph \\ ${ }^{4}$ Bicol University Polangui Campus, Polangui, Albay, Philippines, fsrelucio@bicol-u.edu.ph \\ ${ }^{5}$ Bicol University Polangui Campus, Polangui, Albay, Philippines, ben.saminiano@gmail.com
}

\begin{abstract}
The concept of bringing comfort to homes through the process of utilizing the Internet of Things (IoT) in the development of an electrical system is the main focus of the study. It was anchored on development of interface theory for component architecture, diffusion of innovation theory and the IoT. It sought to determine the following: the design of the system using IoT; the developed electrical system; the performance of the system in terms of activation and response time; and the significant difference on the response time according to groups. The output of the study was derived using the rapid application development (RAD) methodology. The NodeMCU microcontroller was coded in the Arduino IDE and needs internet connection in order to be controlled by the installed application and can remotely operates the socket regardless of distance using an android smart phone. SSID and wifi password was set and the user interface for the app was designed using the MIT app inventor and ThingkSpeak as the open IoT platform. The result for the activation time shows that the internet speed faster the activation time. The mean average for the response time of the four sampled group areas are within the third limit of user perception of 10 seconds. The analysis of variance shows that the $F$ value is below the F critical value at level of significance of 0.01 . Thus, there is no significant difference in response time according to groups.
\end{abstract}

Key words : Electrical outlet, electrical system, home automation, IoT, smart home.

\section{INTRODUCTION}

The Internet of Things or IoT, is a collection of interrelated computing devices, mechanical and digital machines, objects, animals or individuals that have unique identifiers (UIDs) and the ability to transmit data over a network without the need for human-computer contacts [1]. These devices also communicate with similar devices, and act on each other's knowledge they receive. The machines do much of the work without human intervention, while people can, for example, communicate with the machines, set them up, send them instructions or access the data [2]. The access, networking and communication protocols used with these web-enabled devices are focused largely on the various IoT applications [3].

Several studies have conducted to present a framework in order to develop a device using Internet of Things (IoT). With IoTs progressing, the use factor has changed from computers to every device human uses. [4,5]. IoT helps organizations to connect and interact with each other every day to provide inhabitants and consumers with information, data, and services. IoT is known as the most interesting recent work in the current era of computing. IoT seeks to provide mankind with a simpler and healthier life. It allows people, physical devices, data, and application to link over the internet to allow remote control of integrated services and interactive services [5,6]. IoT technology can help human work in information needs, utilize information, and provide information to the surrounding environment. One of the applications of IoT that helps humans with information gathering is control or monitoring activities that are controlled through commonly used devices [5,7]. Initially the IoT was most important for industry and manufacturing. Its technology is often referred to as machine-to-machine (M2M), but now it is about filling homes and offices with smart devices, making it something that's important for almost everyone [8]. With continuing technical progress, the IoT is increasingly being applied in a variety of fields, such as home automation.

A home automation helps users to monitor different kinds of electrical appliances. Home automation using the cloud network is a system that uses computers or mobile devices to monitor basic home functions and features from anywhere in the world, automatically via the internet [9]. This system differs from other systems due to its ability to access and operate anywhere over the internet [10]. Home automation uses in-home controller. Through the use of a stationary or wireless interface, the user can control their home devices. Internet connectivity made globally controlled system 
possible with the use of mobile devices and personal computers [11]. IoT made home automation possible like controlling electrical and electronic home appliances like fan, lights, fire alarm, and kitchen timer remotely over the cloud [12]. IoT can transform any physical object and be controlled when they are connected to the Internet. Through the use of IP address assigned to a device, it can be monitored and accessed remotely [13].

Looking beyond the home and the contribution of several studies about IoT, the researchers developed an electrical outlet system using IoT that may give a solution in responding to the needs of home automation. Specifically, it sought to answer the following questions: (1) what is the design of the system using internet of things (IoT)?; (2) how will the electrical system be developed?; (3) what is the performance of the system in terms of activation time and response time?; and (4) what is the significant difference on the response time according to groups?

\section{METHODOLOGY}

Issues related to stress-causing matters are slowly being addressed by technologies and IoT technology has somehow provided comfort to humans. Remote automation and sensing were made possible through this technology [14]. Interface automata was used in the development of interface theory for a component architecture. Then, the "accessors" provide an actor-oriented proxy for devices and services which forms the architecture for IoT [15].

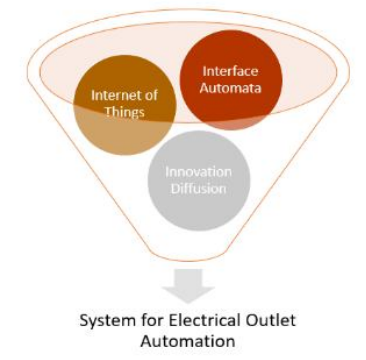

Figure 1: Theoretical Paradigm

Furthermore, Diffusion of Innovation (DOI) Theory is one of the oldest social science theories. This occurred from communication to explain how an idea or object gains momentum over time and diffuses (or spreads) over a particular population or social network. The end result of this diffusion is that as part of a social network, people adopt a new idea, practice or product. The key to acceptance is that the idea or product must be viewed as new or imaginative. It is by this that diffusion can be made [16,17]. Thus, the theoretical framework or paradigm shown in Figure 1 of this research portray the system for electrical outlet automation with infused theory of IoT which is perceived to be an innovation to address the needs of human for comfort and ease of doing things.
The study used the workflow of the system development using the Rapid Application Development (RAD) model [18] as shown in Figure 2. For requirements planning, the researchers identified the hardware and software requirements of the projects. The NodeMCU [19], ThingSpeak [20], MIT App inventor [21] and Tuniot for ESP8266 wifi microchip [22], are the main requirement of the system. The output of this study is beneficial to the household consumers wherein the developed system would lessen fire-related cases in their household due to unplugged

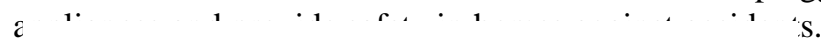

\section{Figure 2: Rapid Application Development (RAD) Methodology}

For the user design phase, the main design, program flowchart and the isometric lay-out of the device were drafted to fit the system's requirement. The study innovates an outlet that can be controlled by an android application with internet access to control the device in the domain and would serve as a device and programmed to automatically switch (on/off) the electrical outlet. It focused on controlling appliances anywhere that are plugged in to the outlet.

In the construction phase, the coding for the NodeMCU was performed by the researchers using Tuniot. The user interface program was then coded using MIT App inventor for the android app. Then the outlet was connected to the NodeMCU and fixed inside the modular box. The modular box served as the casing of the device which composed of the following: NodeMCU, wifi microchip, three-way switch, $5 \mathrm{v}$ two-channel relay and electrical wires. During the user design and construction phases, the prototype was refined and tested for optimum performance. The system is to be plugged to the main source of current then the appliance like air conditioning unit would be plugged in the outlet of the system. Once the appliance is plugged in the system's electrical outlet, the user can now remotely turn on/off the appliance. Then, to determine the performance of the device, the following appliances were used: lamp, electric fan, cellular phone charger and $0.5 \mathrm{hp}$ air conditioning unit using two different internet connections: PLDT Home Fiber at $15 \mathrm{mbps}$ and Smart cellular data at 5 mbps.

Finally, in the evaluation phase, the researchers install the design and created the prototype of the system. Testing and evaluation of the activation and response time of the system 
are conducted to know it the system would satisfy the standard response time of an IoT device. The significant difference of the response time between and within groups were also determined using Analysis of Variance (ANOVA). The device is limited to appliances that operate within 10 amperes per socket. Appliances that exceed the maximum capacity may damage the IoT device.

\section{RESULTS AND DISCUSSIONS}

This section presents the results of the IoT electrical outlet development, the design of the system using IoT, the development of the electrical outlet system using IoT, the performance of the system in terms of activation time and response time, and the significant difference on the response time according to groups.

\subsection{Design of the System using IoT}

Figure 3 shows the block diagram of the system. The USB adapter converts the $220 \mathrm{AC}$ power supply to $5 \mathrm{v}$, to power the NodeMCU. When activated in an android phone by the on/off command from the android app, the NodeMCU will signal the two-channel $5 \mathrm{v}$ relay driver operated by the $5 \mathrm{v}$ mini power supply. The relay driver determines which relay to activate to turn the outlet on or off through the three-way switch.

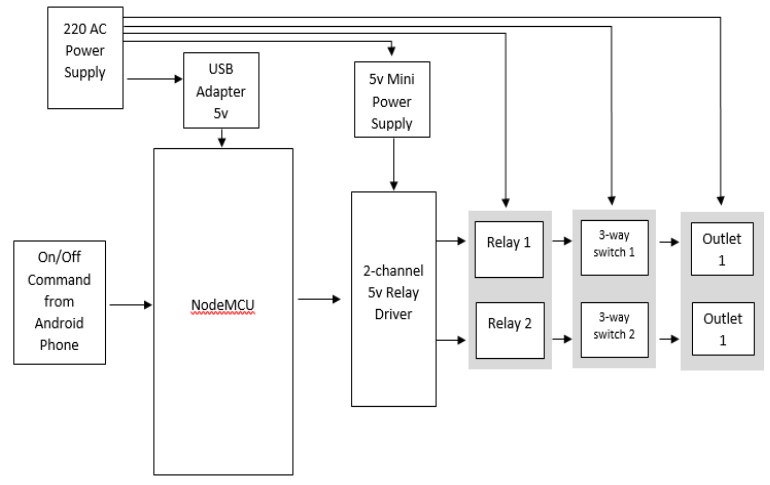

Figure 3: Block Diagram of Electrical Outlet System using IoT

The system's main component is the NodeMCU microcontroller. It was chosen by the researchers due to its powerful microprocessor capability with inbuilt TCP/IP and WiFi support along with a good microprocessor, without the need for heavy processing and multi-threading. It is comparable to Arduino Uno but it has fewer GPIO, ADC and PWM options than the Uno. It supports serial communication protocols that lets the user connects a GPIO extender or another microcontroller if needed. Likewise, the Raspberry Pi was also considered but not cost effective to this project. The versatility and low cost offered by NodeMCU is much more preferred by the researchers. The functionalities of this microcontroller were deemed fit to this project. In the programming side, it is asynchronous and event-driven. Many functions have parameters for callback functions, such functionality was considered, though in the initial planning, the system does not need complex and heavy codes.

The 5-volt two-channel relay functions switch opens and electromechanically closes circuits. Relays monitor one electrical circuit by the opening and closing of contacts in another. It turns on and off the system mainly based on MCU command. The device was designed for simplicity, flexible and ease of use. This IoT-based electrical outlet system used a microprocessor in its packaging and is thus reprogrammable, making it more flexible. This can expand in one kit to more electrical outlets, and can be individually operated. In addition, every form of plug will be catered for by one outlet as a result of using universal socket recognized within the Philippine setting.

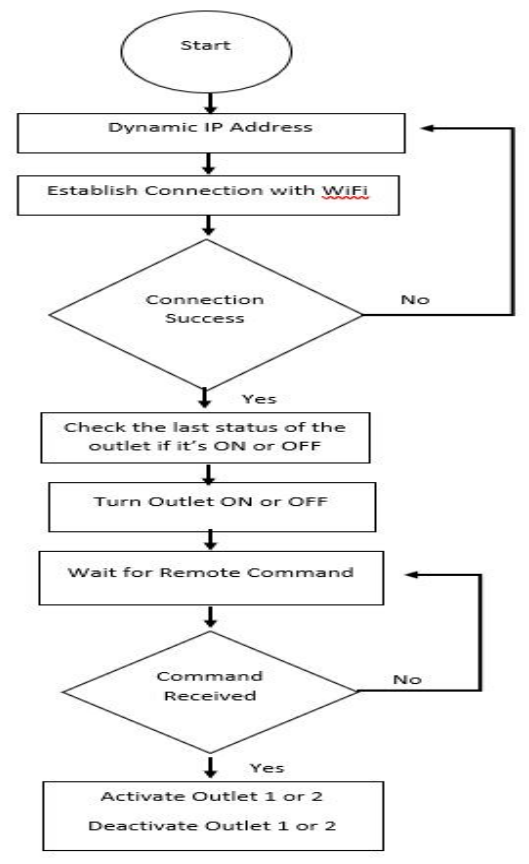

Figure 4: Program Flow Chart

In Figure 4, the flowchart of the program is shown. The program started by assigning a dynamic IP address to establish connection to the internet. Once the connection is successful, the device checks the last status of the outlet if it is on or off, otherwise it goes back to the assigning of IP address. After the status was checked, the device activates the outlet then it waits for the command of the user from the android app to turn the outlet on or off. When the button is pressed, it sends the signal to activate the chosen outlet for the appliance to turn on/off.

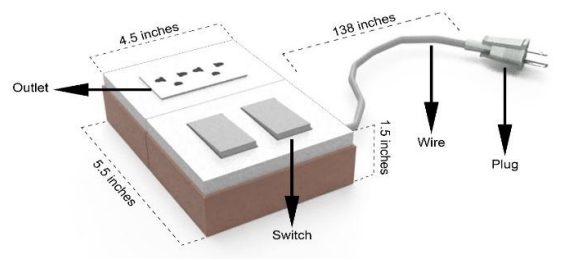

Figure 5: Isometric Lay-out of the Device 
The isometric lay-out of the device is shown in Figure 5. The plastic modular box which serves as the casing is a rectangular prism with length of 5.5 inches, with of 4.5 inches and height of 1.5 inches. At the top of the prism are the outlets and switches. Attached to the prism is the 138 inches number 14 electrical wire with the attached male plug.

\subsection{Development of the Electrical Outlet System using IoT}

This stage is the layout the connections of the actual components. The researchers initially used the breadboard, battery and LEDs to check if the connection is established. Figure 6 shows the conducted actual initial wiring and testing. The connections for the relay wiring was fixed first followed by the wirings for the MCU. The live wire was connected to the live-in socket of outlet 1 and to a common line to the live-in socket of outlet 2 . From the neutral line it is connected to the common 0 socket of the three-way switch 1 and to a common line to the common 0 socket of switch 2 . From socket 1 traveler of the three-way switch 1 , it was connected to the normally open socket of Relay 1 . From the normally closed relay 1 to the socket 3 traveler of the three-way switch 1 , the common of the 1 was connected to the neutral socket of outlet 1 to complete the circuit.

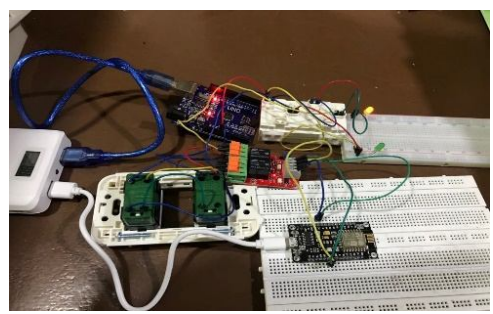

Figure 6: Initial Wiring conducted for testing using $5 v$ power supply

Since there was a common line connection of the neutral line in common 0 , the researchers connected socket 2 traveler on the three-way switch 2 . It was tapped to the normally open socket of Relay 2 . Then, from the normally closed of relay 2 to the socket 3 traveler of the three-way switch 2 . Then, it was connected to the common of relay 2 to the neutral socket of outlet 2 to complete the circuit. The power of the NodeMCU was supplied by the USB 5v and used a 220v to 5v module to power up the two-channel relay module with respect to the ground. The NodeMCU now has the ability to energize the relay for the ON and OFF of the 1 and 2.

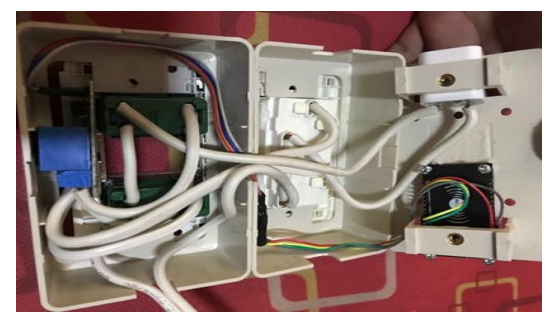

Figure 7: Casing and Components inside the Modular Box

When the device was finalized, series of initial test were conducted by the researcher. In the initial design, the researcher used the NodeMCU 3.3V to power the relay which based from the specification of the relay it can be powered by 3.3 volts which is also the power output of the NodeMCU.

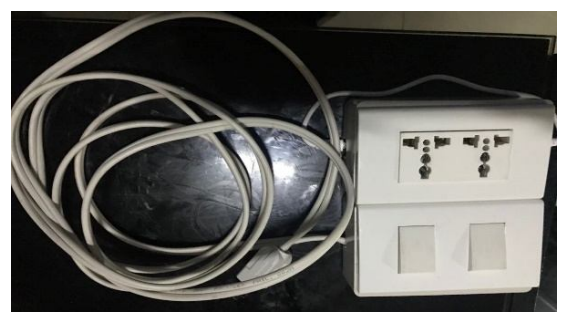

Figure 8: Outside view of the Electronic Outlet System

In the initial test conducted, one socket performed well but the other socket hardly responded to the command. It was also observed that it takes longer time for the relay to respond to command sent by the microprocessor. Therefore, the researchers analyzed the situation and found out that the 3.3 volts power cannot fully sustain the relay.

Consequently, the researchers tried to use the mini power supply module that converts the $220 \mathrm{AC}$ direct source to 5 volts. Providentially, the solution applied worked remarkably in the system. Then, the casing used for the device socket is the ordinary electrical modular box used for wall mounting. The components were positioned inside the box, some components were screwed, some used the knots included in the module and several wires were soldered. Figure 7 shows the casing and component position inside the modular box, while Figure 8 shows the outside view of the casing.

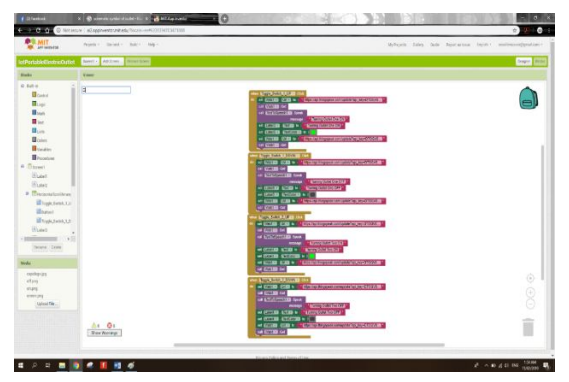

Figure 9: Android App Programming using the MIT App Inventor 2

There were two programming activities conducted. The first is the programming for the android application using the MIT app Inventor 2 and the second programming was for the NodeMCU. Figure 9 shows the actual codes and the interface of the MIT app inventor while Figure 10 shows the actual interface output of the program. In the interface, there are a total two (2) pairs of on and off buttons representing the two (2) outlets. The user would press the on or off button depending on their desired command. The second programming was for the NodeMCU and the Arduino IDE was used. During this programming stage, the wifi credentials were inputted. The program was transferred through USB to the NodeMCU. 


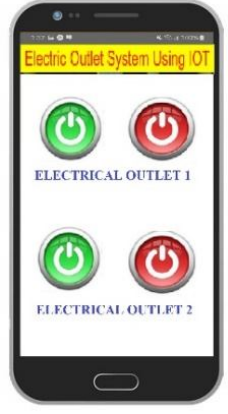

Figure 10: User Interface of the Application

For the interfacing stage, the android mobile application and the outlet were interfaced via the internet through an open IoT platform. Specifically, the researchers used ThingSpeak as the Open IoT platform to generate Application Programming Interface (API) key. Figure 11 shows the ThingSpeak trial chart for 1 outlet. The two (2) in the y-axis is the on command while three (3) is the off command. The $\mathrm{x}$-axis shows the time the trials were performed.

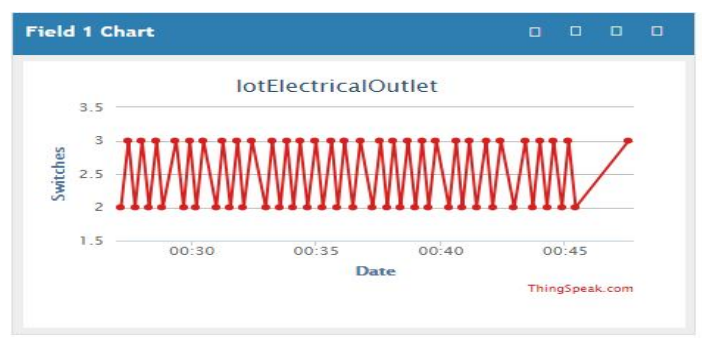

Figure 11: ThingSpeak Trial Chart

Before the evaluation process, system testing was performed for the testing of activation and response time, the researchers tested the sockets and manual switch if it responds accordingly. Figure 12 shows the actual testing using a small lamp.

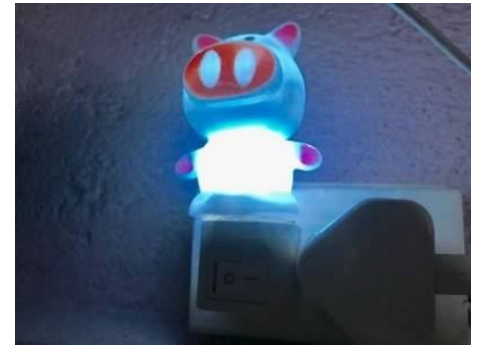

Figure 12: System Testing

\subsection{Performance of the System}

The researchers evaluated the activation and response time of the system by recording the time in seconds. For the activation time, this was tested by observing the duration in seconds using ISP1 and ISP2. The system was activated from the time it was plugged in to the $\mathrm{AC}$ outlet to the time the device was ready to accept command from the user.
Table 1: Activation Time

\begin{tabular}{|c|c|c|}
\hline \multicolumn{3}{|c|}{ Recorded Activation Time in Seconds } \\
\hline \multirow{3}{*}{ Trials } & ISP1 & ISP2 \\
\cline { 2 - 3 } & $\begin{array}{c}\text { PLDT Home Fiber at } \\
15 \mathrm{mbps}\end{array}$ & $\begin{array}{c}\text { Smart Cellular Data at } \\
5 \mathrm{mbps}\end{array}$ \\
\hline 1 & 10.30 & 18.90 \\
\hline 2 & 9.01 & 15.90 \\
\hline 3 & 11.15 & 15.70 \\
\hline 4 & 13.80 & 19.99 \\
\hline 5 & 12.40 & 17.20 \\
\hline Mean & 11.33 & 17.54 \\
\hline
\end{tabular}

The researchers conducted ten (10) trials using two (2) different internet connections. Table 1 shows the recorded activation time for five (5) trials per internet line. It was noted that using ISP1 the shortest time was 9.01, the longest time was 13.80 , then, the mean is 11.33 secs. With ISP2 the shortest time recorded was 15.70 , the longest time is 19.99 and the mean is 17.54 secs. With the data recorded, it is considered that the speed of the internet greatly affects the activation time of the system.

The researchers also evaluated the response time of the system using four (4) different appliances for testing. The researchers used lamp, cellular phone charger, electric fan and air conditioning unit. The internet connection used in this test is the PLDT Home Fiber which gives more favorable result on the activation time conducted. Table 2 shows the mean of on and off trials for twenty-five (25) times conducted on four (4) different appliances. The mean for on and off trials in secs of the system with lamp is 7.63 secs. and 9.43 secs. with an average of 8.53 secs. For the cellular phone charger, 8.32 and 9.46 respectively, with an average of 8.89 secs. In testing the electric fan, the mean for on is 9.91 secs. and 8.91 secs. for off with an average of 9.41 secs. The air conditioning unit got 9.79 and 10.25 respectively with an average of 10.02 secs.

Table 2: Response Time

\begin{tabular}{|l|c|c|c|}
\hline \multicolumn{4}{|c|}{ Response Time in Seconds } \\
\hline \multirow{2}{*}{ Appliances Sampled } & \multicolumn{2}{|c|}{ Mean } & \multirow{2}{*}{$\begin{array}{c}\text { Average } \\
\text { Mean }\end{array}$} \\
\cline { 2 - 3 } & On & Off & 8.53 \\
\hline Lamp & 7.63 & 9.43 & 8.89 \\
\hline Cellular Phone Charger & 8.32 & 9.46 & 9.41 \\
\hline Electric Fan & 9.91 & 8.91 & 10.02 \\
\hline Air Conditioning Unit & 9.79 & 10.25 & \\
\hline
\end{tabular}

With respect to the user's 3rd limit of latency/response time perception which is around 10 secs. limit the user's attention to the context [23]. The researchers compared the recorded below the 10 secs limit average mean of lamp, cellular phone 
Maria Charmy A. Arispe et al., International Journal of Advanced Trends in Computer Science and Engineering, 9(1.3), 2020,280 - 286

charger and electric fan. The average mean for the air conditioning unit which is 10.02 can also be considered acceptable.

\subsection{Significant Difference on the Response Time}

Table 3: Test for Significant Difference using ANOVA

\begin{tabular}{|c|c|c|c|c|c|}
\hline $\begin{array}{c}\text { Sources } \\
\text { of } \\
\text { Variatio } \\
\text { n }\end{array}$ & $\begin{array}{c}\text { Degrees } \\
\text { of } \\
\text { Freedo } \\
\text { m }\end{array}$ & $\begin{array}{c}\text { Sum of } \\
\text { Square } \\
\text { s }\end{array}$ & $\begin{array}{c}\text { Mean } \\
\text { Square } \\
\text { s }\end{array}$ & $\begin{array}{c}\text { Com } \\
\text { puted }\end{array}$ & $\begin{array}{c}\text { Tabu } \\
\text { lar }\end{array}$ \\
\hline $\begin{array}{c}\text { Between } \\
\text { Groups }\end{array}$ & 3 & 31.61 & 10.54 & 3.34 & 3.99 \\
\hline $\begin{array}{c}\text { Within } \\
\text { Groups }\end{array}$ & 96 & 302.85 & 3.15 & & \\
\hline Total & 99 & 334.46 & & & \\
\hline
\end{tabular}

The data used to test the significant difference of the four (4) samples groups were the response time from the test of performance. Table 3 shows the results of the data analysis using Analysis of Variance (ANOVA). As shown in Table 3, the level of significance used is 0.01 with the corresponding $F$ critical value from the $\mathrm{F}$ distribution table of 3.99 at degrees of freedom of (3.96). The computed 3.34 F value is less than the F critical which means that the null hypothesis can be accepted. Thus, it has been concluded that there is no significant difference between the four (4) sample groups.

\section{CONCLUSION}

The electrical outlet system using IoT has NodeMCU main hardware component that served as the brain of the system. The device must be connected to the internet in order to be controlled by the mobile application installed in an android smart phone and remotely operates the socket regardless of distance. The development of the electrical outlet system using IoT started from the identification and acquisition of the materials needed. The software development for the NodeMCU microcontroller was coded in the Arduino IDE and the SSID and Wi-Fi password was set. The user interface for the application was designed using the MIT App Inventor and ThingSpeak as the open IoT platform. The performance of the device was tested by evaluating the activation and response time of the system. For the activation time, the average shows that the higher the speed of the internet the faster the activation time. The mean averages of the four (4) sampled group area for the response time are all within the 3rd user perception limit of 10 secs, indicating device output is within the appropriate limit. The ANOVA shows that the F value at a significance point of 0.01 is below the $\mathrm{F}$ critical value. Then, the null hypothesis is accepted claiming that there is no significant difference in response time per groups.

\section{REFERENCES}

1. TechnoSIP. Internet of Things (IoT). Available Online at https://www.technosip.com/internet-of-things-iot/

2. M. Rouse. Networking and communications - Internet of Things (IoT). IoT Agenda.June 30, 2018. Available Online at https://internetofthingsagenda.techtarget.com/ definition/Internet-of-Things-IoT

3. Smart Card America. Internet of Things (IoT). Available Online at https://www.technosip.com /internet-of-things-iot/

4. K. Suresh, PVGD P. Reddy, P. Pushkal. Smart Home Services Using Cloud and Internet of Things. International Journal of Advanced Trends in Computer Science and Engineering, Volume 8, No.4, July-August 2019. doi.org/10.30534/ijatcse/2019/79842019 Available Online at http://www.warse.org/ IJATCSE/static/pdf/ file/ijatcse79842019.pdf

5. R. Stephen and D. vinoth Kumar. Deist: Dynamic detection of sinkhole attack for internet of things. International Journal of Advanced Trends in Computer Science and Engineering, 5 (12), 19358-19362. 2016. doi:10.18535/ijecs/v5i12.16. Available Online at https://www.ijitee.org/download/volume-8-issue-5

6. A. A. A. Gad-Elrab, A. E. Shereen, N. I. Ghali, A. A. S. Zaghrout. A Dynamic Genetic-Based Context Modeling Approach in Internet of Things Environments. International Journal of Advanced Trends in Computer Science and Engineering, Volume 8, No.6, November-December 2019. doi.org/10.30534/ ijatcse/2019/ 03862019. Available Online at http://www.warse.org/IJATCSE/static/pdf/file/ijatcse03 862019.pdf

7. S. G. Bunawan, M. Aldenny, D. I. Setiani, G. Wang. Architecture Internet of Things Based on Cluster Housing Security System Using Fog Computing. International Journal of Advanced Trends in Computer Science and Engineering, Volume 8, No.6, November December 2019. doi.org/10.30534/ijatcse/2019/ 68862019. Available Online at http://www.warse.org/ IJATCSE/static/pdf/file/ijatcse68862019.pdf; https://

8. S. Ranger. What is the IoT? Everything you need to know about the Internet of Things right now. ZDNet, February 3, 2020. Available Online at https://www.zdnet.com/article/what-is-the-internet-of-th ings-everything-you-need-to-know-about-the-iot-right-n ow/

9. M. Kanchana, B. A. Kannan and D. Jaiganesh. Home automation security and storage system using cloud computing. International Journal for Scientific Research \& Development (IJSRD), Vol. 3, Issue 1, pp. 93-97. January 2015. Available Online at http://ijsrd.com/Article.php?manuscript=IJSRDV3I100 6

10. K. N. Vinay Sagar and S. M. Kusuma. Home automation using Internet of Things. International Research Journal of Engineering and Technology 
(IRJET), Vol. 2, Issue 3, January 2015. Available Online at https://www.irjet.net/archives/V2/i3/Irjet-v2i3317.pdf

11. Electronics, Projects, Focus (ELPROCUS). Wireless

Home Automation using IoT. 2019. Available Online at https://www.elprocus.com/wireless-home-automation-us ing-internet-of-things/

12. A. Lady. PIR Motion Sensor. 2019. Available Online at https://learn.adafruit.com/pir-passive-infrared-proximit y-motion-sensor?view=all

13. International Data Corporation (IDC). IDC Forecasts Worldwide Spending on the Internet of Things to Reach \$772 Billion in 2018. December 7, 2017. Available Online at https://www.idc.com/getdoc.jsp? containerId=prUS43295217; https://www.businesswire. com/news/home/20171207005963/en/IDC-Forecasts-W orldwide-Spending-Internet-Things-Reach

14. K. Stansberry, J. Anderson and L. Rainie. The internet will continue to make life better. Pew Research Center, Internet \& Technology, October 28, 2019. Available Online at https://www.pewresearch.org/internet/ 2019/10/28/4-the-internet-will-continue-to-make-life-be tter/

15. M. Papert and A. Pflaum. Development of an ecosystem model for the realization of internet of things (IoT) services in supply chain management. Electronic Markets, 27(2), 175-189. 2017. Available Online at https://ideas.repec.org/a/spr/elmark/vyid10.1007_s1252 5-017-0251-8.html

16. A. M. Al-Momani, M. A. Mahmoud and M. S. Ahmad. Modeling the adoption of internet of things services: A conceptual framework. International Journal of Applied Research,2(5), 361-367, 2016. Available Online at http://www.allresearchjournal.com/archives/ ?ArticleId $=1933 \&$ issue $=5 \&$ part $=F \&$ vol $=2 \&$ year $=2016$

17. Boston University School of Public Health. Behavioral Change Models - Diffusion of Innovation Theory. Available Online at http://sphweb.bumc.bu.edu/otlt/ MPH-Modules/SB/BehavioralChangeTheories/Behavior alChangeTheories4.html

18. C.T. Lucidchart. 4 Phases of Rapid Application Development Methodology. 2018. Available Online at https://www.hokuapps.com/blogs/rapid-application-dev elopment/

19. NodeMCU. NodeMCU Documentation. 2019. Available Online at https://nodemcu.readthedocs.io/en/ master/

20. Mathworks. ThingSpeak. 2019. Available Online at https://www.mathworks.com/help/thingspeak/

21. AppInventor. App building made easy. 2019. Available Online at http://www.appinventor.org/

22. Easy Coding. Tuniot for Esp8266. 2019. Available Online at http://easycoding.tn/index.php/nodemcu/

23. Z. Yang and T. Nakajima. Connecting smart objects in IoT architectures by screen remote monitoring and control. Computers, 7(4), p. 47. 2018. Available Online at https://doi.org/10.3390/computers7040047 